La Revue

des Droits

de l'Homme

\section{La Revue des droits de l'homme}

Revue du Centre de recherches et d'études sur les droits fondamentaux

Actualités Droits-Libertés | 2011

Obligation de consultation préalable des groupes ethniques (cour constitutionnelle colombienne)

\title{
Contrôle de constitutionnalité d'une révision constitutionnelle et contrariété à un traité international intégré au bloc de constitutionnalité
}

obligation de consultation préalable des groupes ethniques (cour constitutionnelle colombienne)

\section{Carolina Vergel Tovar}

\section{OpenEdition}

Journals

Édition électronique

URL : http://journals.openedition.org/revdh/3706

DOI : $10.4000 /$ revdh.3706

ISSN : 2264-179X

\section{Éditeur}

Centre de recherches et d'études sur les droits fondamentaux

\section{Référence électronique}

Carolina Vergel Tovar, "Contrôle de constitutionnalité d'une révision constitutionnelle et contrariété à un traité international intégré au bloc de constitutionnalité ", La Revue des droits de l'homme [En ligne] Actualités Droits-Libertés, mis en ligne le 05 janvier 2011, consulté le 01 mai 2019. URL : http:// journals.openedition.org/revdh/3706 ; DOI : 10.4000/revdh.3706 


\section{Contrôle de constitutionnalité d'une révision constitutionnelle et contrariété à un traité international intégré au bloc de constitutionnalité}

obligation de consultation préalable des groupes ethniques (cour constitutionnelle colombienne)

\section{Carolina Vergel Tovar}

1 La Cour constitutionnelle colombienne a déclaré l'article $n^{\circ} 2$ de l'Acte Législatif $n^{\circ} 1$ du 14 avril de 2009 contraire à la Constitution. Ce texte modifiait ainsi l'article 108 de la Constitution politique colombienne: "Les partis et mouvements politiques ayant obtenu leur personnalité juridique à la suite de leur qualification spéciale comme minorités ethniques, pourront autoriser des candidatures sans autre condition que l'affiliation de ces dernières à un tel parti politique, et ce postérieurement à la date d'inscription » de ces partis ou mouvement comme minorités ethniques. Il convient de noter qu'en Colombie, les Actes Législatifs («actos legislativos ») - à la différence des lois ordinaires - sont des textes portant révision de la Constitution (article 375 de la Constitution). Mais ils sont pourtant exposés à un contrôle de constitutionnalité spécifique: selon l'article 379 de la Constitution Politique colombienne, ces actes (ainsi que les lois qui approuvent un referendum constituant ou la réunion d'une Assemblée Nationale Constituante), peuvent être déclarés inconstitutionnels s'ils contreviennent aux dispositions régissant la procédure de révision de la constitution (Titre XIII, articles 374 - 380), sous réserve cependant que le recours mettant en cause leur constitutionnalité soit présenté dans un délai d'une année après la promulgation dudit acte (article 379 al. 2).

2 Pour fonder sa décision en l'espèce, la Cour constitutionnelle a commencé par rappeler que la consultation préalable des communautés ethniques sur toutes les "mesures législatives ou administratives susceptibles de les toucher directement" est un droit 
fondamental qui découle de leur droit à la participation à de telles décisions politiques, à la libre détermination, à l'autonomie et à l'intégrité culturelle. Un tel droit est reconnu de manière expresse par l'article 6 de la Convention 169 de l'OIT relative aux peuples indigènes et tribaux, instrument qui, par l'intermédiaire de l'article 93 de la Constitution Politique, fait partie du bloc de constitutionnalité. De la même manière, la Cour a rappelé que cette consultation des communautés ethniques est une condition préalable aux discussions de toute mesure législative et ne peut être satisfaite par la seule existence des espaces généraux de discussion, au sein ou hors du processus législatif.

Selon la Cour, la notion de «mesure législative » prévue par l'article 6 de la Convention 169 de l'OIT inclut les «Actes Législatifs » - au sens de la Constitution colombienne - car cette stipulation conventionnelle vise, à travers un mécanisme de participation efficace, à assurer la préservation effective de la culture des communautés ethniques. La Cour fait donc ici une interprétation extensive de la notion de «mesure législative» en incluant « tout type de mesures législatives et non administratives » et qualifie comme telle les mesures qui « permettent d'élargir le spectre d'exercice du droit fondamental des communautés ethniques ». Dans le cas d'espèce, la Salle plénière de la Cour (« la sala plena de la Corte »), a constaté qu'il n'y avait pas eu de consultation préalable des communautés ethniques directement concernées au sujet de la disposition législative dont la constitutionnalité était ici mise en cause. La Cour a d'ailleurs demandé au Président du Parlement plus d'informations à ce sujet, mais sans succès.

4 Les enjeux de la décision sont plus perceptibles par le biais des opinions dissidentes, deux magistrats ayant justifié plus avant leur refus de voter en faveur de la déclaration d'inconstitutionnalité. D'une part, selon le Magistrat M. González, la consultation préalable fait référence seulement à l'adoption des lois et des actes administratifs qu'affectent directement les communautés ethniques et non pas aux actes réformateurs de la Constitution - c'est à dire les "Actes Législatifs » ici en question. Les instruments comme la Convention 169 de l'OIT peuvent servir de paramètres d'interprétation des droits et des devoirs constitutionnels dans la mesure où ils se révèlent plus protecteurs que la Constitution elle-même. Et ce n'est que dans ce cas où ils pourront être appliqués à la place du texte constitutionnel lui-même.

5 D'autre part, le Magistrat H. Sierra Porto a justifié son vote en soulignant que : (1) en premier lieu, la décision majoritaire révèle l'absence de paramètres normatifs pour l'exercice du contrôle de constitutionnalité des actes législatifs. Selon lui, ce contrôle paraît plus dépendre des critères fixés par la majorité à l'occasion de la discussion de chaque cas particulier que d'une véritable démarche rigoureuse, ce qui rend le contrôle constitutionnel plus politique que juridique. (2) En deuxième lieu, selon le magistrat, cette décision créerait une nouvelle catégorie en matière de vices d'inconstitutionnalité. Outre les vices d'ordre formel et des vices de "substitution de la Constitution", il y aurait maintenant des vices "formels d'ordre substantiel" ou vices de compétence. (3) En troisième et dernier lieu, cette nouvelle catégorie de vice pourrait conduire à l'extension aux réformes constitutionnelles de la théorie du "caractère irréparable des vices ", théorie déjà utilisée pour le contrôle de constitutionnalité des lois ordinaires (brièvement, la nature réparable ou irréparable des vices de constitutionnalité conditionne le sort du recours: son admission si le vice est irréparable mais son possible rejet si le vice est finalement " réparé », ainsi que le délai du recours, celui-ci étant étendu dans l'hypothèse d'un vice irréparable). 
Cour Constitutionnelle colombienne, Sentencia C-702/10, 15 décembre 2010, M.P. Jorge Ignacio Pretelt Chaljub.

\section{AUTEUR}

\section{CAROLINA VERGEL TOVAR}

Carolina Vergel Tovar est Maîtresse de conférences du Département de droit constitutionnel à l'Université Externado de Colombie. Membre de la ligne de recherche en sociologie du droit « revendications sociales et droit » 